\title{
T Cells Recognize an Immunodominant Epitope of Heat Shock Protein 65 in Kawasaki Disease
}

\author{
Guido Sireci, ${ }^{1}$ Francesco Dieli, ${ }^{1}$ and Alfredo Salerno ${ }^{1,2}$ \\ ${ }^{1}$ Section of Pathology, Department of Biopathology, University of Palermo, \\ Palmero, Italy \\ ${ }^{2}$ Institute of Advanced Diagnostic Methodologies (ISMEDA), National Research \\ Council, Palermo, Italy
}

Accepted May 8, 2000

\begin{abstract}
Background: Kawasaki disease (KD) is an acute systemic vasculitis of infancy and early childhood that is characterized by endothelial cell damage associated with T-cell activation. Lymphocytes infiltrating damaged tissues might be responsible for the disease through secretion of cytokines, such as tumor necrosis factor (TNF)- $\alpha$, that could cause fever, as well as endothelial tissue damage. Debate is growing about the nature of antigen responsible for T-cell activation in KD. Bacillus Calmette Guèrin (BCG) and purified protein derivative (PPD) hyperresponsiveness was observed in KD patients and this phenomenon was hypothetically ascribed to cross-reactivity between mycobacterial Heat Shock Protein (HSP) 65 and human homologue HSP63.
\end{abstract}

Materials and Methods: $\mathrm{CD}^{+}$and $\mathrm{CD}^{+}$T-cell clones were obtained from peripheral blood of KD patients in acute phase, or control subjects. The clones were tested for reactivity toward HSP65 and derived peptides. Both proliferation and cytokine production were analyzed.

Results: A significant fraction of CD4 and CD8 T-cell clones from KD patients recognized an epitope from HSP65, spanning amino acids 65-85. T-cell clones cross-reacted with the corresponding 90-110 peptide sequence of human HSP-63.

Conclusions: Cross-reactivity between specific epitopes of mycobacterial and human HSP could play a role in the development of the tissue-damage characteristic of KD.

\section{Introduction}

Kawasaki disease (KD) is an acute systemic vasculitis of infancy and early childhood that is characterized by prolonged fever, conjunctivitis, inflammation of the oropharynx, rash, erythematous induration of the distal extremities, and cervical lymphadenopathy (1). Coronary artery abnormalities can develop in up to $25 \%$ of untreated patients (2). The introduction of high-dose intravenous immune globulin (IVIG) in combination with aspirin treatment, within the first 10 days after the onset of fever,

Address correspondence and reprint requests to: Prof. Alfredo Salerno, Institute of Advanced Diagnostic Methodologies (ISMEDA), National Research Council, Corso Tukory 21 1, 90134 Palermo, Italy. Phone: ++39 091 6555902; Fax: ++39091 6555901;

E-mail: asalerno@unipa.it has significantly reduced the prevalence of coronary artery abnormalities in KD (3). Early recognition and prompt treatment is, therefore, critical to achieve successful outcomes. Unfortunately the current definition of $\mathrm{KD}$ is based on diagnostic criteria that use clinical features which overlap with other illnesses. This creates diagnostic dilemmas in atypical cases, which do not completely fulfil the diagnostic criteria of KD, but are associated with the development of coronary artery abnormalities (4).

Numerous reports have documented that acute $\mathrm{KD}$ is associated with increased immune activation. Studies of tissues from children dying of acute KD have revealed marked generalized vascular inflammation of small and mediumsized blood vessels, particularly the coronary arteries $(5,6)$. The initial vascular lesion in KD 
is associated with endothelial cell activation and up-regulation of cytokine-induced leukocyteadhesion molecules, accompanied by the infiltration of neutrophils and mononuclear cells. The mononuclear cell infiltrate consists of both activated $\mathrm{CD}^{+}{ }^{+}$and $\mathrm{CD}^{+} \mathrm{T}$ cells, as well as monocyte/macrophages. This state of immune activation is accompanied by elevated levels of interleukin (IL) - $1 \beta$ (7) and tumor necrosis factor (TNF) $-\alpha$ (8). Successful treatment of KD patients with IVIG plus aspirin is associated with a reduction in their elevated cytokine production and endothelial cell activation (9).

It has been hypothesized that the activation of $\mathrm{T}$ cells and monocyte/macrophages found in acute KD is a feature of diseases caused by bacterial toxins that act as superantigens (10). Staphylococcal enterotoxin, toxic shock syndrome toxin-1 (TSST-1), could be responsible for this immune activation binding directly to a particular $\mathrm{T}$ cell receptor (TCR) $\mathrm{V} \beta$ like $\mathrm{V} \beta 2$ or $\mathrm{V} \beta 8.1$, whose percentages are increased during acute KD and return to normal levels after treatment with IVIG plus aspirin (11).

In addition, hyperreactivity to Bacillus Calmette Guèrin (BCG) (12) and purified protein derivative (PPD) (13) has been reported in KD patients that could be due to cross-reactivity between mycobacterial heat shock protein (HSP)65 and the human homologue HSP63 (14). A possible pathogenic role of HSP63 in KD was enforced by the increased expression of the human HSP63 gene in peripheral blood of patients (15). To analyze the possible role of HSP during the acute phase of KD, we determined at a clonal level the presence of $\mathrm{T}$ lymphocytes recognizing HSP65.

\section{Materials and Methods}

\section{Patients and Controls}

A total of 5 patients $(3$ males and 2 females, aged from 3 months to 5 years, mean: 2 years and 4 months) were diagnosed as having Kawasaki disease, according to the 1984 revised criteria (4). They had been hospitalized within 7 days of the onset of fever. One patient revealed meningitis diagnosed after prolonged headache, computed tomography (CT) scanning and mononuclear cells count in cerebrospinal fluid (CSF).

Tuberculin-PPD skin test was considered positive when the skin induration diameter was $>5 \mathrm{~mm}$ at $48-72 \mathrm{hr}$ after injection of $1 \mathrm{U}$ of PPD (Statens Seruminstitut, Copenhagen,
Denmark). All the blood samples were collected at the admission during the acute phase of disease, before drug treatment, and 5-7 days after the tuberculin skin test had been performed. Control samples were obtained from age-matched children who had a positive tuberculin skin test.

\section{Preparation of T-cell Clones}

The previously described methodology (16) was used with minor modifications. Briefly, CD4 and CD8 T lymphocytes were isolated from peripheral blood lymphocytes (PBL) or CSF cells by immunomagnetic sorting (Miltenyi Inc., Sunnyvale, CA) and cultured in (RPMI) 1640 medium (Gibco, Grand Island, NY) with $10 \%$ heat-inactivated pooled human AB serum. Wells of U-bottomed 96-well plates (Nunc, Roskilde, Denmark) were seeded with $10^{4} \mathrm{~T}$ cells, supplemented with $2 \times 10^{5}$ allogeneic PBL (irradiated at 3,000 rads from a Cesium source), $5 \times 10^{4}$ irradiated Epstein Barr Virus (EBV)-induced autologous lymphoblastoid cells (BCL), $0.5 \mu \mathrm{g} / \mathrm{ml}$ leukoagglutinin (Sigma, St. Louis, MO) and $200 \mathrm{U} / \mathrm{ml}$ human recombinant IL-2 (Genzyme, Cambridge, MA) in a total volume of $0.2 \mathrm{ml}$. After 21 days of culture, the cells were transferred to tissue culture flasks and further expanded in the presence of $200 \mathrm{U} / \mathrm{ml}$ of IL-2. The cell lines were $92-98 \%$ $\mathrm{CD}^{+}$or $\mathrm{CD}^{+}$by fluorescence-activated cell sorting (FACS) analysis. Cloning at 0.3 cells/well in the medium, supplemented as in the initial cell culture, yielded a $40-100 \%$ plating efficiency. The average frequency of positive wells was about $15 \%$, which corresponded to an estimated growth frequency of $60 \%$ under limiting dilution conditions, following a single-hit Poisson distribution (data not shown). T-cell clones were used for the proliferation assay at least 3 days after the last IL-2 addition. This cloning procedure, using phytohemagglutinin (PHA) and allogeneic stimulation, induced expansion of virtually all CD4 and CD8 T cells and did not introduce any bias into the T-cell repertoire $(17,18)$.

\section{Antigens and Synthetic Peptides}

PPD was obtained from Statens Seruminstitut, Copenaghen, Denmark. The recombinant mycobacterial HSP65 (clone MA-5C) was a generous gift of Dr. J. van Embden (World Health Organization Bank). Synthetic peptides spanning already reported immunodominant regions of the mycobacterial HSP65 sequence 
were synthesized by g-fluorenylmethylcarbonil (Fmoc) technology using trialkoxydiphenyl-methylester resin and Castro's reagent for coupling as described elsewhere $(19,20)$. After cleavage with trifluoroacetic acid and deprotection, the peptides were purified by reverse-phase high performance liquid chromatography (HPLC) in $0.1 \%$ trifluoroacetic acid/acetonitrile, followed by gel filtration through Sephadex G15 in $\mathbf{2 5 \%}$ acetic acid in water. Homogeneity and purity were confirmed by analytical reverse phase HPLC, mass spectrometry, amino acid composition analysis, and sequence fidelity by Edman degradation.

\section{T-cell Clones Proliferation Assay}

$\mathrm{CD}^{+}$and $\mathrm{CD}^{+}$T-cell clones were cultured in triplicate at $5 \times 10^{4} /$ well with $2.5 \times 10^{5} /$ well irradiated EBV-transformed autologous B lymphoblastoid cells (BCL) as antigen presenting cells (APC) and antigen concentrations ranging from 0.1 to $10 \mu \mathrm{g} / \mathrm{ml}$ or synthetic peptides at the concentration $50 \mu \mathrm{g} / \mathrm{ml}$. Preliminary analysis showed that peptides gave optimal proliferation at $50 \mu \mathrm{g} / \mathrm{ml}$ and, therefore, only results obtained using this antigen dose are presented. Proliferation was set up in a final volume of $0.2 \mathrm{ml}$ in 96 flat-bottomed microtitre plates (Nunc, Copenaghen, Denmark), at $37^{\circ} \mathrm{C}$ in the presence of $5 \% \mathrm{CO}_{2}$. Three days later, $37 \mathrm{kBq}$ (1 $\mu \mathrm{Ci}$ )/well $\left[{ }^{3} \mathrm{H}\right]$ thymidine (Amersham, Buckinghamshire, U.K.) was added and the cultures were harvested $18 \mathrm{hr}$ later. The radioactive incorporation was determined by standard liquid scintillation counting. Results are expressed as Stimulation Index (SI), i.e. mean counts per minute $(\mathrm{cpm})$ in the presence of antigen divided by mean cpm in the absence of antigen. Responses to PPD or individual peptides were considered positive if the SI was $>3$. Standard deviation (SD) values of mean radioactive counts usually did not exceed $10 \%$ of the mean cpm values.

\section{Lymphokine ELISA Assay}

Triplicate cultures of cloned T cells at $5 \times 10^{4} /$ well with $2.5 \times 10^{5}$ irradiated autologous $\mathrm{BCL} /$ well as antigen presenting cells were stimulated with 0.1 to $10 \mu \mathrm{g} / \mathrm{ml}$ of HSP65 or PPD, or with $50 \mu \mathrm{g} / \mathrm{ml}$ of HSP65-derived synthetic peptides. Cultures in a final volume of $0.2 \mathrm{ml}$ in flat-bottomed 96 -well microtitre plates (Nunc), were incubated at $37^{\circ} \mathrm{C}$ in the presence of $5 \% \mathrm{CO}_{2}$ for $24-48 \mathrm{hr}$. Culture supernatants were harvested and tested for IL-2 or TNF- $\alpha$ content by two-monoclonal antibodies (mAbs) sandwich ELISA (Pharmingen, San Diego, CA), according to manufacturer's recommendations. Sensitivity of assays was $30 \mathrm{pg} / \mathrm{ml}$ for both IL-2 and TNF- $\alpha$.

\section{Statistics}

The double-Student's $t$-test was used to analyze statistical significance between control and experimental groups. Values of $p>0.05$ were considered nonsignificant.

\section{Results}

Increased Frequency of PPD- and HSP65-specific T-cell Clones in KD Patients

$\mathrm{CD}^{+}$and $\mathrm{CD}^{+}{ }^{+} \mathrm{T}$-cell clones were obtained from peripheral blood of KD patients in acute phase and the percentage of clones recognizing PPD and HSP65 was assessed in a proliferative assay. Table 1 shows that a very large fraction of both CD4 and CD8 T-cell clones from KD patients vigorously proliferated to PPD and HSP65 in vitro, with $44 \%$ of the CD4 and $34 \%$ of the CD8 clones specifically recognizing HSP65. Note from Table 1 that the number of clones recognizing HSP65 was virtually identical to that of clones recognizing the whole PPD antigen, thus, suggesting that recognition of HSP65 primarily was responsible for PPD recognition. Proliferation of five typical CD4 and CD8 T-cell clones from KD patients to HSP65 is shown in Figure 1. Of interest, HSP65 was recognized by only $9 \%$ CD4 and 7\% CD8 PPD-specific T-cell clones obtained from five different control individuals with a positive PPD skin test.

\section{IL-2 and TNF-a Levels in T-cell Clones from KD Patients}

To analyze the functional activity of HSP65specific T-cell clones, a total of $38 \mathrm{CD}^{+}$and 28 $\mathrm{CD}^{+} \mathrm{T}$-cell clones from all five KD patients were tested for IL-2 and TNF- $\alpha$ production. Cytokines production by a typical $\mathrm{CD}^{+}$and a typical $\mathrm{CD}^{+}{ }^{\mathrm{T}}$-cell clone are shown in Figure 2. Both CD4 and CD8 clones produced IL-2 (Fig. 2A) and TNF- $\alpha$ (Fig. 2B) in response to HSP65 stimulation in vitro. However, a comparison of the cytokine levels showed that CD4 clones produced much more IL-2 than did CD8 clones; whereas, the reciprocal pattern was found for TNF- $\alpha$ production. 
Table 1. Frequency of T-cell clones proliferating to PPD and mycobacterial HSP65

\begin{tabular}{|c|c|c|c|}
\hline \multirow{2}{*}{\multicolumn{2}{|c|}{$\begin{array}{l}\text { KD Patients } \\
(n=5)\end{array}$}} & \multicolumn{2}{|c|}{$\begin{array}{l}\text { Number (\%) } \\
\text { of Clones } \\
\text { Reactive to }\end{array}$} \\
\hline & & \multirow{2}{*}{$\begin{array}{c}\text { PPD } \\
7 / 18(39)\end{array}$} & \multirow{2}{*}{$\begin{array}{c}\text { HSP65 } \\
7 / 18(39) \\
5 / 21(24)\end{array}$} \\
\hline$\# 1$ & $\begin{array}{l}\mathrm{CD} 4 \\
\mathrm{CD} 8\end{array}$ & & \\
\hline$\# 2$ & $\begin{array}{l}\text { CD4 } \\
\text { CD8 }\end{array}$ & $\begin{array}{r}11 / 21(53) \\
6 / 16(38)\end{array}$ & $\begin{array}{r}10 / 21(48) \\
5 / 16(31)\end{array}$ \\
\hline \#3 & $\begin{array}{l}\text { CD } 4 \\
\text { CD8 }\end{array}$ & $\begin{array}{l}9 / 16(56) \\
8 / 15(53)\end{array}$ & $\begin{array}{l}9 / 16(56) \\
7 / 15(47)\end{array}$ \\
\hline$\# 4$ & $\begin{array}{l}\text { CD4 } \\
\text { CD8 }\end{array}$ & $\begin{array}{l}5 / 14(36) \\
5 / 13(39)\end{array}$ & $\begin{array}{l}5 / 14(36) \\
5 / 13(39)\end{array}$ \\
\hline \#5 & $\begin{array}{l}\text { CD4 } \\
\text { CD8 }\end{array}$ & $\begin{array}{l}7 / 17(42) \\
6 / 16(38)\end{array}$ & $\begin{array}{l}7 / 17(42) \\
6 / 16(38)\end{array}$ \\
\hline & Total CD4 & $39 / 86(45)$ & $38 / 86(44)$ \\
\hline & Total CD8 & $30 / 81(37)$ & $28 / 81(34)$ \\
\hline
\end{tabular}

Healthy Controls $(n=5)$

\begin{tabular}{lc}
\hline Total CD4 & $10 / 110(9)$ \\
Total CD8 & $5 / 75 \quad(7)$
\end{tabular}

Results represented in bold are statistically significant, compared with controls $(p<0.001)$. Proliferating clones were derived from different limiting dilution plates of different patients or controls. Only PPD-specific T-cell clones from controls subjects were tested for HSP65 reactivity in vitro. PPD, purified protein derivative; HSP65, heat shock protein 65 .

Proliferative Responses of KD- or Controls-derived T-cell Clones to Peptides from HSP65

The fine epitope specificity of HSP65-specific CD4 and CD8 T-cell clones was investigated using peptides corresponding to known immunodominant regions of this protein. Figure 3 shows the proliferative response of CD4 and CD8 T-cell clones to different epitopes of HSP65. Peptide 65-85 was recognized by 35 out of 38 HSP65-specific CD4 clones and by 24 out of 28 HSP65-specific CD8 clones. Peptides 198-2 17, 277-293, 283-298, and 422-436 were not recognized at all by either CD4 and CD8 clones from KD patients. Using truncated variants of the 65-85 peptide, we found that CD8 T-cell clones did not recognize peptides spanning aminoacids 70-85 and 69-85, thus, indicating that residues located at positions 65-70 were crucial for CD8 recognition (Fig. 3A). Conversely, peptides 70-85 and 69-85 were recognized by CD4 clones as efficiently as was peptide $65-85$, thus, indicating that CD4 clones recognized a shorter peptide sequence located at amino acids 70-85. Of note, the 65-85 peptide was not recognized at all by HSP65-specific T-cell clones from control individuals (Fig. 3B), which most frequently recognized peptide 198-217.

These data were reinforced by IL- 2 and TNF- $\alpha$ measurement after stimulation with HSP65 peptides. In fact, CD4 and CD8 T-cell clones from KD patients produced IL-2 (Fig. $4 \mathrm{~A}$ ) and TNF- $\alpha$ (Fig. 4B) in response to the 65-85 peptide.

\section{Frequency and Epitope-reactivity of T-cell Clones from PBL and CSF}

To investigate the possible pathogenic role of HSP65-specific cells, we analyzed the fre-
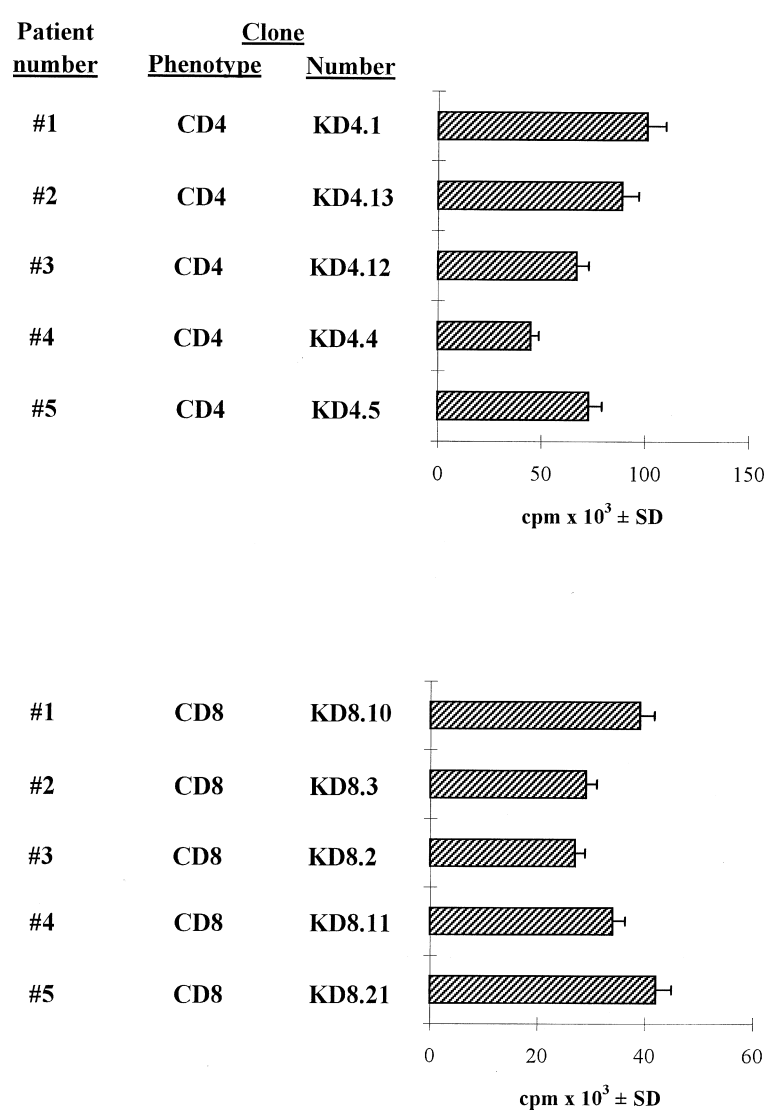

Fig. 1. Proliferative response to HSP65 of $\mathrm{CD}^{+}$or $\mathrm{CD8}^{+}$T-cell clones obtained from Kawasaki disease (KD) patients. Five representative $\mathrm{CD}^{+}{ }^{+}$and $\mathrm{CD} 8^{+}$T-cell clones obtained from Kawasaki disease (KD) patients were stimulated in vitro with heat shock protein (HSP) $65(10 \mu \mathrm{g} / \mathrm{ml}$, final concentration) and autologous antigen presenting cells. cpm, mean counts per minute; SD, standard deviation. 
A. IL-2

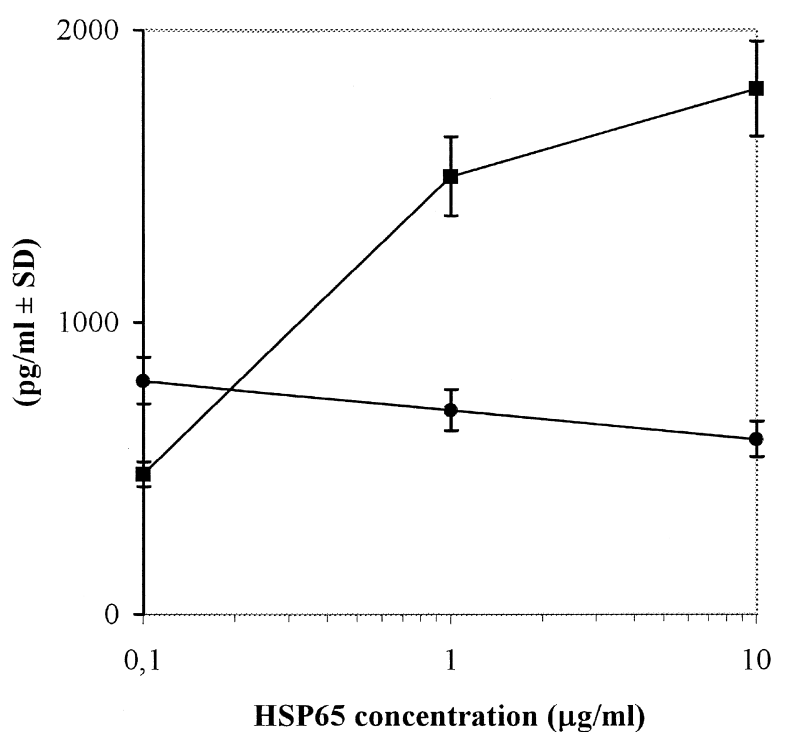

Fig. 2. IL-2 and TNF- $\alpha$ production of $\mathrm{CD4}^{+}$ and $\mathrm{CD8}^{+} \mathrm{T}$ cell clones from patients to HSP65. One representative $\mathrm{CD}^{+}(\boldsymbol{\square})$ and one representative $\mathrm{CD}^{+}(\mathbf{O}) \mathrm{T}$-cell clone from Kawasaki disease (KD) patients were stimulated with different

quency and epitope specificity of HSP65 T-cell clones derived from the CSF of the one patient with associated meningitis. Figure 5 shows that $39 \%$ of the CD4 and $41 \%$ of CD8 T-cell clones from CSF recognized HSP65, indicating compartmentalization of HSP65-specific CD4, and especially, of CD8 T cells at the site of disease.

The fine specificity of the HSP65-reactive T-cell clones was then investigated using different HSP65 peptides. Both CD4 and CD8 T-cell clones from CSF recognized the 65-85 peptide. Moreover, CD8 T-cell clones did not recognize peptides spanning $69-85$ and $70-85$ amino acids; whereas, CD4 T-cell clones recognized a shorter sequence between residues 70-85. Upon stimulation in vitro with the whole HSP65 protein or its $65-85$ peptide, the T-cell clones from KD patients produced discrete amounts of IL-2 and TNF- $\alpha$. From these results we concluded that HSP65-specific CD4 and CD8 T-cell clones with identical epitope specificity were compartmentalized at sites of disease during the acute phase of KD.

Cross-reactivity of KD T-cell Clones Between Human HSP63- and Mycobacterial HSP65-derived Peptide

Since homology between 65-85 amino acidic sequence of mycobacterial HSP65 and 90-110 se-
B. TNF- $\alpha$

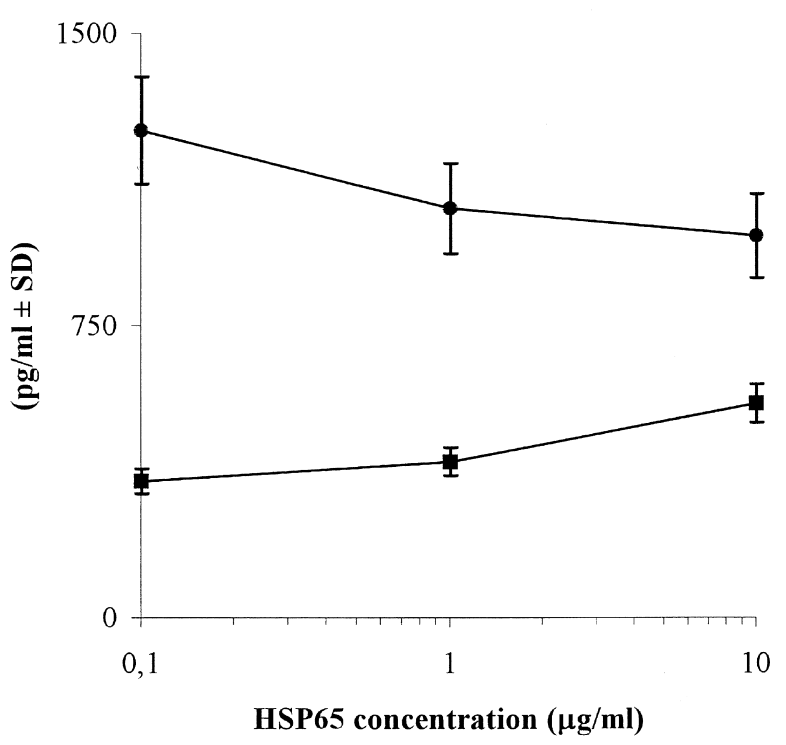

amounts of recombinant heat shock protein (HSP) 65. (A) Interleukin (IL)-2 and (B) tumor necrosis factor (TNF) $-\alpha$ productions were quantified in culture supernatants by ELISA, as described in "Materials and Methods." SD, standard deviation.

quence of human HSP63 (55\%) (Table 2) was found, we assessed if the same clones reacting to the mycobacterial HSP65-derived 65-85 peptide also recognized the 90-110 peptide of the homologue human protein. As shown in Table 3, 75\% (21 out of 28 ) of CD8 and $60 \%$ (23 out of 38 ) of CD4 T-cell clones from KD patients proliferating to the 65-85 peptide of mycobacterial HSP65 also recognized peptide 90-110 of human HSP63, indicating cross-reactivity between mycobacterial- and human-HSP at the clonal level and suggesting a possible pathogenic role of HSP-specific T cells in KD.

\section{Discussion}

Acute KD is characterized by a marked immune activation. Several investigators have reported increased numbers of activated T cells, as identified by enhanced expression of human leukocyte antigen (HLA)-DR molecules and serum IL-2 receptor levels $(21,22)$. Furthermore, acute $\mathrm{KD}$ is associated with increased production of IL- $1 \beta$, TNF- $\alpha$, IL-2, IL-6, and IFN- $\gamma$ (23-25). The production of these cytokines by $\mathrm{T}$ cells and monocytes is thought to have an important role in the pathogenesis of 


\section{A. KD patients}

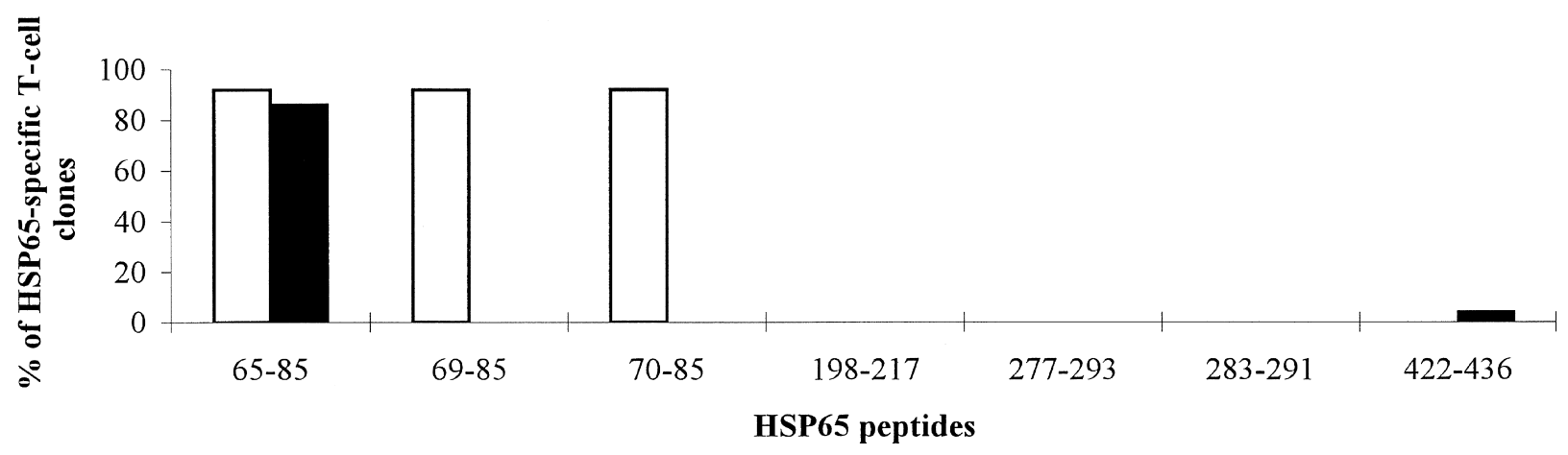

\section{B. Control subjects}

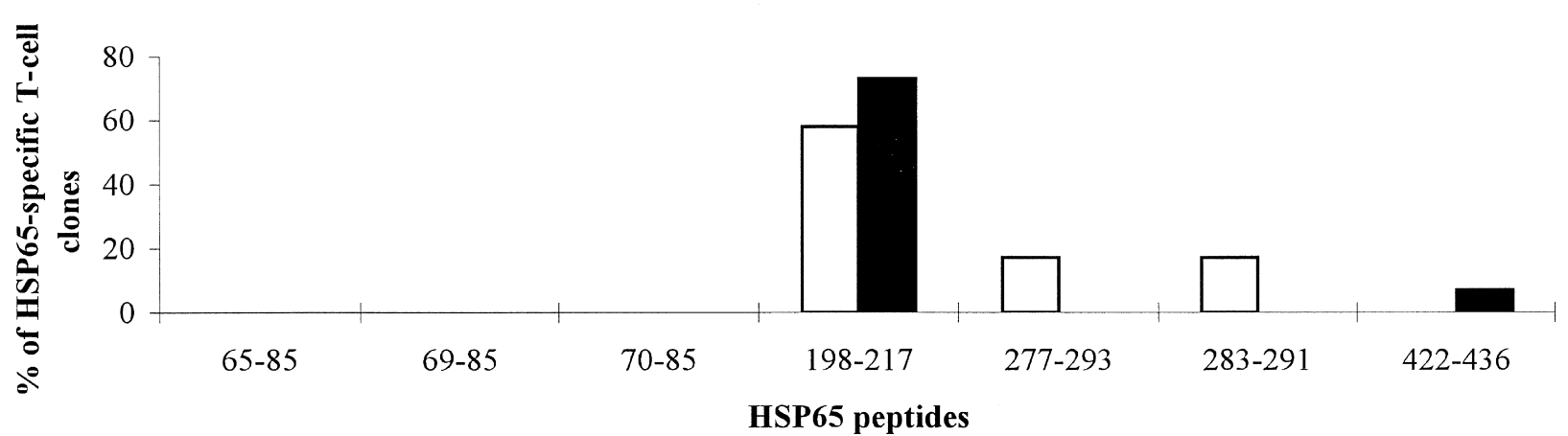

Fig. 3. Frequency of HSP65-specific T-cell clones proliferating to various peptides. $\mathrm{CD} 4^{+}$ (ם) and $\mathrm{CD}^{+}(\square)$ T-cell clones were tested in proliferative response to various peptides.

$\mathrm{KD}$, especially in vascular endothelial cell injury (26). It is widely believed that $\mathrm{KD}$ is caused by an infectious agent, because it is selflimiting, prone to strike young children, and has epidemic outbreaks. The etiologic agent is still unknown.

Evidences in the literature support the idea that the immune system in KD is stimulated by superantigens that directly bind major histocompatibility complex (MHC) class II molecules to cause activation of macrophages and B cells and selectively stimulates $\mathrm{T}$ cells expressing variable domains of the $\beta$ chain of TCR, such as $\mathrm{V} \beta 2$ and $\mathrm{V} \beta 8$.1. This possibility has been supported by the reported increased frequencies of $\mathrm{V} \beta 2$-bearing $\mathrm{T}$ cells in peripheral blood of acute KD patients (11). Additionally, it is possible that HSP65 contributes to the abnormally activated immune system of patients with acute KD via a molecular mimicry between mycobacterial HSP65 and human HSP63 (27). This hypothesis is suggested by the increased expres-
Percentages of responsive clones for single epitope are shown. KD, Kawasaki disease; HSP65, heat shock protein 65 .

sion of HSP63 mRNA in peripheral blood of KD patients (15) and the presence of antibodies to mycobacterial HSP65 and autoantibodies to epitopes of human HSP63 cognate antigen (28).

Results reported in this paper clearly show an increased frequency of PPD- and mycobacterial HSP65-specific CD4 and CD8 T-cell clones in KD patients. These clones produce cytokines, such as IL-2 and TNF- $\alpha$, which could play an important role in the pathogenesis of KD. Thus, TNF- $\alpha$ could be relevant to endothelial tissue damage and fever that are characteristic of KD. In fact, a correlation between fever and TNF- $\alpha$ serum levels has been detected in patients affected by KD (23).

The results of fine recognition of distinct peptides of HSP65 by CD4 and CD8 T-cell clones from KD patients are somehow surprising. Both CD4 and CD8 T-cell clones recognize a peptide sequence located between amino acids $65-85$. This peptide is not recognized at all by HSP65-specific CD4 and CD8 T-cell 
A. IL-2

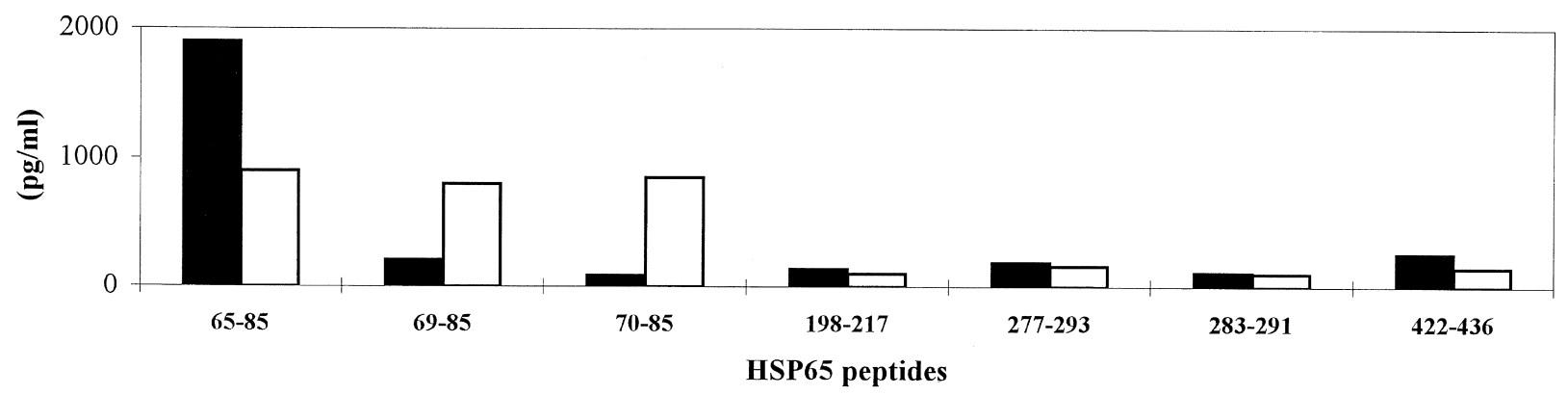

B. TNF- $\alpha$

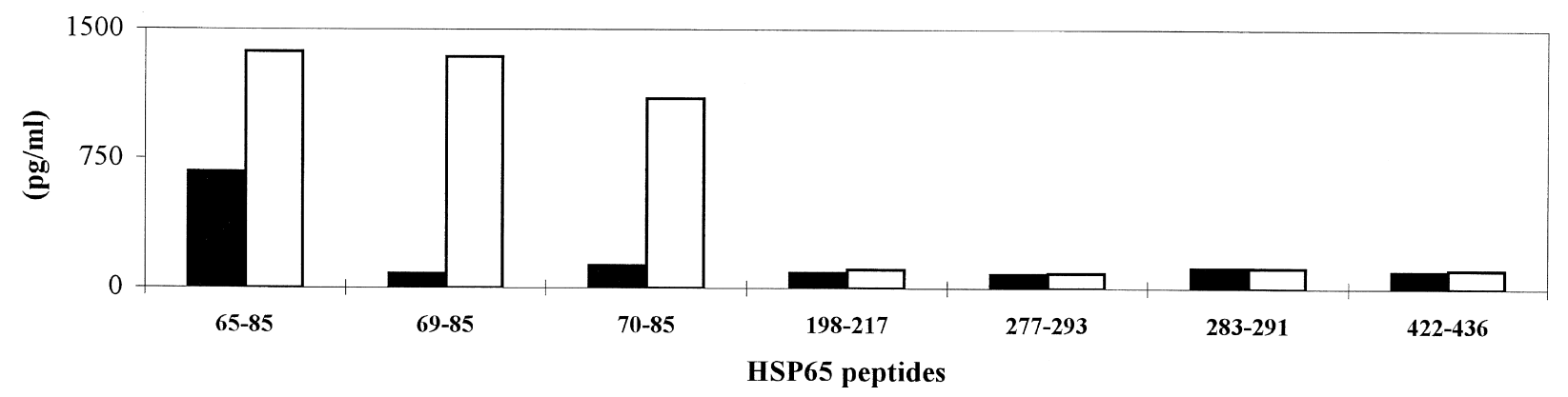

Fig. 4. IL-2 and TNF- $\alpha$ production by T-cell clones of KD patients in response to HSP65peptides. $\mathrm{CD}^{+}(\square)$ and $\mathrm{CD}^{+}(\square)$ T-cell clones from Kawasaki disease (KD) patients were tested for their ability to produce cytokines in response to heat shock protein (HSP)65-derived peptides. IL-2, interleukin-2; TNF- $\alpha$, tumor necrosis factor- $\alpha$.

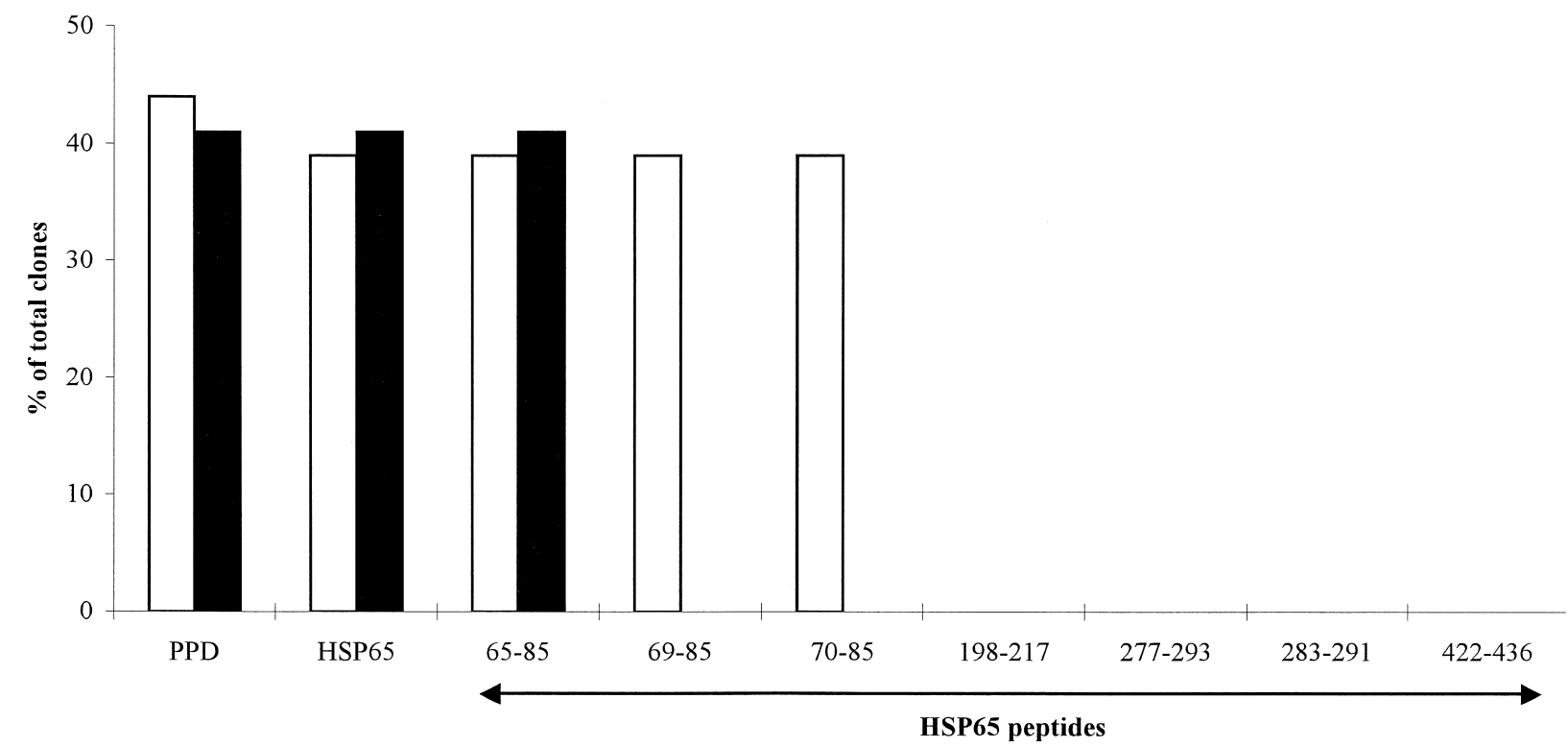

Fig. 5. Pattern of reactivity of $\mathrm{CD4}^{+}$and $\mathrm{CD8}^{+}$ T-cell clones obtained from CSF of a KD patient. $\mathrm{CD}^{+}(\square)$ and $\mathrm{CD}^{+}(\square)$ T-cell clones obtained from cerebrospinal fluid (CSF) of a
Kawasaki disease (KD) patient suffering of meningitis were tested for their proliferative responses to various antigens. Percentages of reactive clones are shown. HSP65, heat shock protein 65. 
Table 2. Peptide sequences of mycobacterial HSP65 epitope and the corresponding human HSP63 epitope, as recognized by $\mathrm{CD4}^{+}$and $\mathrm{CD8}^{+} \mathrm{T}$-cell clones

\begin{tabular}{|c|c|c|c|}
\hline A & Origin of HSP65 Peptide & Amino Acid Sequence & Map Position \\
\hline & Mycobacterium Tuberculosis & $\underline{\text { YEKIGAELVKEVAKKIDDVAG }}$ & $65-85$ \\
\hline & Pl antigen & 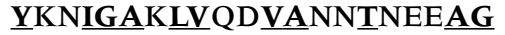 & $90-110$ \\
\hline
\end{tabular}

B

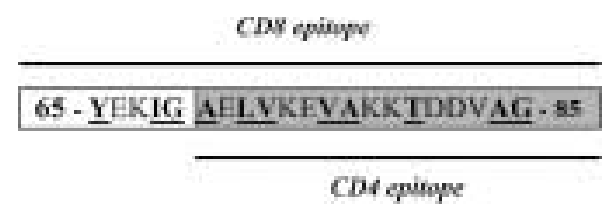

The sequences of mycobacterial HSP65 peptide 65-85 and of the corresponding human HSP63 90-110 peptide are shown. Identical residues are underlined in bold (A). The deduced CD4 and CD8 minimal epitope sequences from the mycobacterial HSP65 65-85 peptide also are shown. Identical residues with the corresponding human HSP63 90-110 peptide are underlined in bold (B). HSP65, heat shock protein 65.

clones derived from control subjects, who otherwise preferentially recognize peptide 198-217 of mycobacterial HSP65. The finding that none of the T-cell clones from KD patients recognize peptide 198-217 can be explained by the low degree of homology (30\%) between the 198-217 amino acidic sequence of mycobacterial HSP65 (ISGYFVTDPERQEAVLEDPY) and the corresponding 224-243 sequence of human HSP63

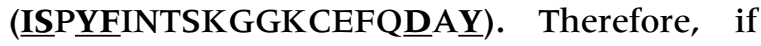

Table 3. Cross-reactivity between peptide 65-85 of mycobacterial HSP65 and peptide 90-110 of human HSP63 protein

\begin{tabular}{lcc}
\hline & $\begin{array}{c}\text { Number (\%) of HSP65 } \\
\text { Clones Recognizing: }\end{array}$ \\
\cline { 2 - 3 } $\begin{array}{l}\text { Mycobacterial } \\
\text { HSP65 Peptides }\end{array}$ & CD4 $^{+}$Clones & CD8 $^{+}$Clones \\
\hline $65-85$ & $35 / 38(92)$ & $24 / 28(86)$ \\
$69-85$ & $35 / 38(92)$ & $0 / 28(0)$ \\
$70-85$ & $35 / 38(92)$ & $0 / 28(0)$ \\
\hline
\end{tabular}

Human HSP63 Peptide

\begin{tabular}{lll}
\hline $90-110$ & $23 / 38(60 \%)$ & $21 / 28(75 \%)$
\end{tabular}

Results indicate the number (\%) of HSP65-specific T-cell clones from KD patients, recognizing both mycobacterial HSP65-derived peptides and human HSP63-derived peptide. (See also the legend to Table 2). HSP65, heat shock protein 65 . reactivity toward HSP is initiated by either mycobacterial or human HSP65 molecule, crossreactivity should involve more conserved regions of the proteins. In any event, dominant recognition of the 65-85 epitope region of the HSP65 protein appears to be a feature unique to KD patients. Moreover, compartmentalization of CD4 and CD8 T-cell clones with the same epitope specificity was found in one patient, strongly suggesting that HSP65-specific CD4 and CD8 clones play a role in the pathogenesis of KD.

These data are in agreement with previous reports on the ability of HSP65 to activate both $\mathrm{CD}^{+}$and $\mathrm{CD}^{+}$T cells (29). Thus, HSP65 would presumably be the cause of the immune activation in KD. Additionally, it is important to understand whether HSP65-specific T cells emerge from bacterial or human HSP65 stimulation. In the former, a critical role for bacteria should be considered, while in the latter, an autoimmune mechanism would play an important role in the pathogenesis of KD. This last possibility is suggested by studies showing that anti-HSP65 antibodies in sera of KD patients recognized an epitope of both mycobacterial HSP65 and its human cognate (28). Interestingly, the target epitopes shared only 2 out of 11 amino acids (i.e. less than $20 \%$ homology).

Comparison of the amino acidic sequence of the mycobacterial HSP65-derived 65-85 peptide and that of the corresponding 90-110 peptide of human HSP63 (Table 2), reveals an 
high degree $(55 \%)$ of homology, with 11 out of 20 amino acids shared between the two sequences. Hence, this finding suggests the possibility that primary exposure to bacterial HSP65 induces immune activation and simultaneous autologous HSP63 expression, which eventually may function as a target for CD4 and CD8 $\mathrm{T}$ cells. Our initial studies indeed indicate that $\mathrm{CD} 4 \mathrm{~T}$-cell clones specific for the 65-85 peptide of mycobacterial HSP65 also cross-recognize the 90-110 peptide of the human HSP63. Alternatively, we cannot actually rule out the possibility that human HSP63 may be primarily expressed as a consequence of endothelial damage or endothelial cell activation. Synthesis of HSP63 can be induced by various cytokines including TNF- $\alpha$ (30), and HSP63 is released into the circulation in response to myocardial ischemia and myocardiocyte injury (31). Thinking more generally, the finding that humoral and cellular reactivity against HSP65/63 has been described in another, more frequent vascular disease, such as atherosclerosis (32), suggests the intriguing possibility that diverse vascular diseases may share a common pathogenetic mechanism involving immune response against HSP65/63.

Taken all together, our results represent the first evidence of the fine specificity of $\mathrm{T}$ cells in $\mathrm{KD}$ and raise the possibility that $\mathrm{T}$ lymphocytes reactive to an immunodominant region of HSP65 may play an important role in the pathogenesis of KD. Furthermore, these observations could explain the cause of hyperreactivity to BCG and PPD in KD patients in acute phase that was attributed to cross-reactivity between mycobacterial HSP65 and its human homologue.

\section{Acknowledgments}

This study was supported by grants from the Ministry for Education and Scientific and Technological Research (MURST; $40 \%$ to A.S. and $60 \%$ to A.S. and F.D.) and the National Research Council (F.D.).

\section{References}

1. Shulman ST, De Inocencio J, Hirsh R. (1995) Kawasaki disease. Pediatr. Clin. N. Am. 42: 12051222.

2. Kato H, Sugimura T, Akagi T, et al. (1996) Long term consequences of Kawasaki disease. A 10-21 year follow-up study of 594 patients. Circulation 94: 1379-1385.
3. Durongpisitkul K, Gururaj VJ, Part JM, Martin CF. (1995) The prevention of coronary artery aneurysm in Kawasaki disease: a meta-analysis on the efficacy of aspirin and immunoglobulin treatment. Pediatrics 96: 1057-1061.

4. The Japan Kawasaki Disease Research Committee. (1984) Report on Diagnostic Guidelines for Kawasaki Disease. Japan Red Cross Medical Center, Tokyo.

5. Fujiwara H, Hamashima Y. (1978) Pathology of the heart in Kawasaki's disease. Pediatrics 61: 100-107.

6. Terai M, Kohno Y, Namba M, et al. (1990) Class II major histocompatibility antigen expression on coronary arterial endothelium in a patient with Kawasaki disease. Hum. Pathol. 21 : 231-234.

7. Leung DYM, Cotran RS, Kurt-Jones E, Burns JC, Newburger JW, Pober JS. (1989) Endothelial cell activation and high interleukin-l secretion in the pathogenesis of acute Kawasaki disease. Lancet vol. 2 (8675): 1298-1302.

8. Lang BA, Silvermann ED, Laxer RM, Lau AS. (1989) Spontaneous tumor necrosis factor production in Kawasaki disease. J. Pediatr. 115: 939-943.

9. Leung DYM, Burns J, Newburger J, Geha RS. (1987) Reversal of immunoregulatory abnormalities in Kawasaki syndrome by intravenous gammaglobulin. J. Clin. Invest. 79: 468472.

10. Kotzin BL, Leung DYM, Kappler J, Marrack P. (1993) Superantigens and their potential role in human disease. Adv. Immunol. 54: 99-166.

11. Abe J, Kotzin BL, Jujo K, et al. (1992) Selective expansion of $\mathrm{T}$-cells expressing $\mathrm{T}$-cell receptor variable regions $\mathrm{V}$ beta 2 and $\mathrm{V}$ beta 8 in Kawasaki disease. Proc. Natl. Acad. Sci. U.S.A. 89: 4066-4070.

12. Kuniyuki S, Asada, M. (1997) An ulcerated lesion at the BCG vaccination site during the course of Kawasaki disease. J. Am. Acad. Dermatol. 37: 303-304.

13. Bertotto A, Spinozzi F, Vagliasindi C, Radicioni M, De Rosa O, Vaccaro R. (1997) Tuberculin skin test reactivity in Kawasaki disease. Pediatr. Res. 41: 560-562.

14. Yokota S. (1991) Heat shock protein as a predisposing and immunopotentiating factor in Kawasaki disease. Acta Paediatr. Jpn. 33: 756-764.

15. Takeshita S, Kawase H, Yamamoto M, Fujisawa T, Sekine I, Yoshioka S. (1994) Increased expression of human $63-\mathrm{kD}$ heat shock protein gene in Kawasaki disease determined by quantitative reverse transcription-polymerase chain reaction. Pediatr. Res. 35: 179-183.

16. David-Ameline J, Lim A, Davodeau F, Bonneville M, Peyrat MA. (1996) Selection of T cells reactive against autologous B lymphoblastoid cells during chronic rheumatoid arthritis. J. Immunol. 157: 4697-4706. 
17. Dieli F, Friscia G, Di Sano C, Sireci G, Titone L, Salerno A. (1999) Sequestration of T lymphocytes to body fluids in tuberculosis: reversal of anergy following chemotherapy. J. Infect. Dis. 180: 225-228.

18. Friscia G, Vordermeier HM, Pasvol G, Harris DP, Moreno C, Ivanyi J. (1995) Human T cell responses to peptide responses of the $16 \mathrm{kD}$ antigen in tuberculosis. Clin. Exp. Immunol. 102: 53-57.

19. Vordermeier HM, Harris DP, Friscia G, et al. (1992) T cell repertoire in tuberculosis: selective anergy to an immunodominant epitope of the 38-kDa antigen in patients with active disease. Eur. J. Immunol. 22: 2631-2637.

20. Oftung F, Mustafa AS, Shinnick TM, et al. (1988) Epitopes of the Mycobacterium tuberculosis 65-Kilodalton protein antigen as recognized by human T cells. J. Immunol. 141: 2749-2754.

21. Terai M, Kohno Y, Namba M, et al. (1990) Class II major histocompatibility antigen expression on coronary arterial endothelium in a patient with Kawasaki disease. Hum. Pathol. 21: 231234.

22. Lang BA, Silverman ED, Laxer RM, Rose V, Nelson DL, Rubin LA. (1990) Serum soluble interleukin-2 receptor levels in KD. J. Pediatr. 116: 592-596.

23. Matsubara T, Furukawa S, Yabuta K. (1990) Serum levels of tumor necrosis factor, interleukin 2 receptor, and interferon- $\gamma$ in Kawasaki disease involved coronary artery lesions. Clin. Immunol. Immunopathol. 56: 29-36.

24. Maury CPJ, Salo E, Pelkonen P. (1989) Elevated circulating tumor necrosis factor- $\alpha$ in patients with Kawasaki disease. J. Lab. Clin. Med. 113: 651-657.

25. Lang BA, Silverman DE, Laxer RM, Lau AS. (1989) Spontaneous tumor necrosis factor production in Kawasaki disease. J. Pediatr. 115: 939-943.

26. Mantovani A, Defana EE. (1989) Cytokines as communication signals between leukocytes and endothelial cells. Immunol. Today 10: 370-375.

27. Meissner HC, Leung DYM. (2000) Superantigens, conventional antigens and the etiology of Kawasaki syndrome. Pediatr. Infect. Dis. J. 19: 91-94.

28. Yokota S, Tsubakin K, Kuriyama T, et al. (1993) Presence in Kawasaki disease of antibodies to mycobacterial heat-shock protein 65 (HSP65) and autoantibodies to epitopes of human HSP65 cognate antigen. Clin. Immunol. Immunopathol. 67: 163-170.

29. Ottenhoff THM, Haanen JBAG, Geluk A, et al. (1991) Regulation of mycobacterial heat-shock protein-reactive $\mathrm{T}$ cells by HLA Class II molecules: Lessons from Leprosy. Immunol. Rev. 121: 171-191.

30. Kiessling R, Gronberg A, Ivanyi J, et al. (1991) Role of HSP60 during autoimmune and bacterial inflammation. Immunol. Rev. 121: 91-111.

31. Schett G, Metzler B, Kleindienst R, et al. (1999) Myocardial injury leads to a release of heat shock protein (hsp) 60 and a suppression of the anti-hsp65 immune response. Cardiovasc. Res. 42: 685-695

32. Wick G, Perschinka H, Xu Q. (1999) Autoimmunity and atherosclerosis. Am. Heart. J. 138: S444-S449. 